\title{
Breakdown of the Linear Relationship between the Southern Hemisphere Hadley Cell Edge and Jet Latitude Changes in the Last Glacial Maximum ${ }^{\mathscr{b}}$
}

\author{
SEO-YeOn KIM AND SeOK-WoO Son \\ School of the Earth and Environmental Sciences, Seoul National University, Seoul, South Korea
}

(Manuscript received 14 July 2019, in final form 4 March 2020)

\begin{abstract}
A poleward displacement of the Hadley cell (HC) edge and the eddy-driven jet latitude has been observed in the Southern Hemisphere ( $\mathrm{SH}$ ) during the last few decades. This change is further projected to continue in the future, indicating coherent tropical and extratropical zonal-mean circulation changes from the present climate to a warm climate. Here we show that such a systematic change in the zonal-mean circulation change does not hold in a cold climate. By examining the Last Glacial Maximum (LGM), preindustrial (PI), and extended concentration pathway 4.5 (ECP4.5) scenarios archived for phase 3 of the Paleoclimate Modeling Intercomparison Project (PMIP3) and phase 5 of the Coupled Model Intercomparison Project (CMIP5), it is shown that while the annual-mean SH HC edge systematically shifts poleward from the LGM scenario to the PI scenario and then to the ECP4.5 scenario the annual-mean SH eddy-driven jet latitude does not. All models show a poleward jet shift from the PI scenario to the ECP4.5 scenario, but over one-half of the models exhibit no trend or even an equatorward jet shift from the LGM scenario to the PI scenario. This decoupling between the $\mathrm{HC}$ edge and jet latitude changes is most pronounced in $\mathrm{SH}$ winter when the Antarctic surface cooling in the LGM scenario is comparable to or larger than the tropical upper-tropospheric cooling. This result indicates that polar amplification could play a crucial role in driving the decoupling of the tropical and midlatitude zonal-mean circulation in the $\mathrm{SH}$ in a cold climate.
\end{abstract}

\section{Introduction}

The atmospheric general circulation is often characterized by the Hadley cell (HC) in the tropics and the eddy-driven jet (hereinafter simply "jet") in the extratropics. These are two key factors that affect global hydroclimate, ocean currents, and air-sea interactions. For instance, the poleward edge of the $\mathrm{HC}$ and its variability modulate precipitation and the water cycle in the subtropics. The jet is closely related to storm track activities, controlling midlatitude precipitation. In the Southern Hemisphere ( $\mathrm{SH})$, the jet also plays a crucial role in determining the Antarctic circumpolar currents and the global overturning circulation in the oceans, affecting the global carbon cycle (e.g., Marshall and Speer 2012).

It is well documented that the latitudinal positions of the $\mathrm{HC}$ edge and jet have recently changed in response

Supplemental information related to this paper is available at the Journals Online website: https://doi.org/10.1175/JCLI-D-190531.s1.

Corresponding author: Seok-Woo Son, seokwooson@snu.ac.kr to global warming and stratospheric ozone depletion. They have shifted poleward during the last few decades in both hemispheres ( $\mathrm{Hu}$ and $\mathrm{Fu}$ 2007; Seidel et al. 2008; Ceppi and Hartmann 2013; Lucas et al. 2014; Lee et al. 2019). Although these changes are often statistically insignificant due to rather short observational records and uncertainties in the reanalysis products (Lucas et al. 2014; Mantsis et al. 2017), they are evident in climate model simulations (Gerber and Son 2014; Grise et al. 2019) particularly in the SH where the long-term trend of circulation is greater than the natural variability (Staten et al. 2018; Grise et al. 2019).

A poleward shift of the $\mathrm{HC}$ edge and jet latitude is further projected to continue in the future climate (Barnes and Polvani 2013; Choi et al. 2014). In particular, the HC expansion is found in most coupled-model simulations. The datasets archived for phase 5 of the Coupled Model Intercomparison Project (CMIP5) (Taylor et al. 2012) show a systematic poleward shift in the $\mathrm{HC}$ edge under various warming scenarios such as the representative concentration pathway (RCP) (Lu et al. 2008; Hu et al. 2013; Choi et al. 2019) and extended concentration pathway (ECP) scenarios (Chavaillaz 
et al. 2013; Son et al. 2018a). Likewise, a poleward shift in the jet latitude is found in the CMIP5 future scenario runs (Barnes and Polvani 2013; Vallis et al. 2015). Although these changes are found in both hemispheres, they are expected to be larger in the $\mathrm{SH}$ than in the Northern Hemisphere (Hu et al. 2013; Barnes and Polvani 2013).

The model simulations further show that the longterm trends of the HC edge and jet latitude are linearly correlated with each other, especially in the SH (Son et al. 2018a; Waugh et al. 2018). Multimodel analyses revealed that their trends in austral summer have a 1:2 ratio, indicating that a poleward shift of the $\mathrm{SH}$-summer jet latitude of $2^{\circ}$ is roughly associated with a poleward shift in the SH-summer HC edge of $1^{\circ}$ (Gerber and Son 2014). Such a linear relationship, which is not evident in the Northern Hemisphere, is also found in the CMIP5 and chemistry-climate model simulations (Son et al. 2018b).

Previous studies are mostly focused on the present and future climate. Only a few studies have explored the $\mathrm{HC}$ edge and jet latitude in a paleoclimate. By comparing the coupled-model simulations archived for the CMIP5 and phase 3 of the Paleoclimate Modeling Intercomparison Project (PMIP3) (Braconnot et al. 2012), D'Agostino et al. (2017) and Son et al. (2018a) showed that the $\mathrm{HC}$ in the Last Glacial Maximum (LGM, 21000 years ago) is narrower than that the one in the preindustrial (PI) condition (D'Agostino et al. 2017; Son et al. 2018a; Wang et al. 2018). Son et al. (2018a) further indicated that the $\mathrm{HC}$ expansion from cold to warm climates is linearly related to global mean surface air temperature change. Specifically, global warming of $10^{\circ} \mathrm{C}$ is associated with an approximately $4.5^{\circ}$ latitude expansion of the $\mathrm{HC}$ width.

Given a systematic HC change from cold to warm climates, the jet latitude is anticipated to change quasilinearly. Toggweiler and Russell (2008) first proposed an equatorward jet shift in the SH in the LGM, arguing that an equatorward-shifted jet might lead a weaker carbon dioxide uptake in the Southern Ocean in the paleoclimate. However, the PMIP3 models showed that the jet in the LGM does not always shift equatorward relative to the PI scenario (Chavaillaz et al. 2013; Rojas 2013; Harrison et al. 2015). Since the HC edge systematically shifts poleward from the LGM to the future scenarios (see also Son et al. 2018b), this gives a hint of a possible decoupling of the $\mathrm{HC}$ edge and jet latitude changes from the PI scenario to the LGM scenario. Their relationship, however, has not been quantitatively examined.

The present study explores the overall relationship between the $\mathrm{HC}$ edge and jet latitude changes in a wide range of climates covering the LGM, PI, and ECP4.5 states. Motivated by Toggweiler and Russell (2008), only the SH circulation is considered as any circulation change in the $\mathrm{SH}$ can be quantified in the zonal-mean context. Unlike previous studies, all available models archived for the PMIP3 and CMIP5 are utilized.

It is confirmed that the $\mathrm{HC}$ edge and jet latitude do not necessarily change in the same direction from the PI scenario to the LGM scenario. This is in stark contrast to a coherent poleward shift of both the $\mathrm{HC}$ and jet from the PI scenario to the ECP4.5 scenario. The decoupling between the $\mathrm{HC}$ edge and jet latitude changes in the LGM is briefly discussed in terms of the interannual covariability, the model mean biases, and the relative importance of tropical versus polar temperature changes. The possible impacts of external thermal forcings on the $\mathrm{HC}$ and jet changes are further explored by conducting idealized model experiments.

\section{Data and methods}

\section{a. PMIP3 and CMIP5 datasets}

This study analyzes the three sets of climate model simulations as in Son et al. (2018a). They are the LGM, PI, and ECP4.5 simulations (Table 1). Note that unlike previous studies that have mainly analyzed the RCP scenarios, this study examines the ECP4.5 scenario, targeting an equilibrium state in the twenty-third century. Expanding upon Son et al. (2018a), who analyzed only six models that provide all three sets of simulations (denoted with an asterisk in Table 1), all available models are used to better quantify the circulation differences between the LGM and PI scenarios and those between the ECP4.5 and PI scenarios.

All analyses are performed with the last 100 years of each simulation. The two exceptions are the ECP4.5 simulations of FGOALS-g2 (2201-75) and CCSM4 (2201-99), whose data records are slightly shorter than 100 years. (Note that expansions of the various climate model acronyms used in this paper can be found online at https://www.ametsoc.org/PubsAcronymList.) Although several models provide multiple ensemble members, only the first ensemble members (r1i1p1) are used by assuming that 100 -year-long data effectively reduce the uncertainty in zonal-mean circulation change. An exception is GISS-E2-R in which the average of the r1i1p150 run and r1i1p151 run for the LGM scenario and the r1i1p142 run for the PI scenario are used because the r1i1p1 run is not available. Each model has a different horizontal resolution ranging from $0.9^{\circ} \times 1.25^{\circ}$ to $2.8^{\circ} \times$ $3.0^{\circ}$ (Table 1). The varying resolutions are interpolated to a common resolution of $2.5^{\circ} \times 2.5^{\circ}$ and at 17 pressure 
TABLE 1. List of CMIP5 and PMIP3 models used in this study. The six models that provide all three experiments (LGM, PI, and ECP4.5) are indicated by asterisks. The experiments analyzed in this study are denoted with "O."

\begin{tabular}{|c|c|c|c|c|c|}
\hline Identifier & Model & Horizontal resolution & LGM & PI & ECP4.5 \\
\hline 1 & $\mathrm{CCSM} 4^{*}$ & $0.9^{\circ} \times 1.25^{\circ}$ & $\mathrm{O}$ & $\mathrm{O}$ & $\mathrm{O}$ \\
\hline 2 & CESM1(CAM5) & $0.9^{\circ} \times 2.5^{\circ}$ & - & $\mathrm{O}$ & $\mathrm{O}$ \\
\hline 3 & CNRM-CM5 ${ }^{*}$ & $1.4^{\circ} \times 1.4^{\circ}(\mathrm{T} 127)$ & $\mathrm{O}$ & $\mathrm{O}$ & $\mathrm{O}$ \\
\hline 4 & COSMOS-ASO & $\mathrm{T} 31\left(3.75^{\circ} \times 3.75^{\circ}\right)$ & $\mathrm{O}$ & $\mathrm{O}$ & - \\
\hline 5 & CSIRO Mk3.6.0 & $1.9^{\circ} \times 1.9^{\circ}$ & - & $\mathrm{O}$ & $\mathrm{O}$ \\
\hline 6 & FGOALS-g2 $^{*}$ & $2.8^{\circ} \times 3^{\circ}$ & $\mathrm{O}$ & $\mathrm{O}$ & $\mathrm{O}$ \\
\hline 7 & GISS-E2-R* & $2^{\circ} \times 2.5^{\circ}$ & $\mathrm{O}$ & $\mathrm{O}$ & $\mathrm{O}$ \\
\hline 8 & IPSL-CM5A-LR* & $1.875^{\circ} \times 3.75^{\circ}$ & $\mathrm{O}$ & $\mathrm{O}$ & $\mathrm{O}$ \\
\hline 9 & IPSL-CM5A-MR & $1.9^{\circ} \times 2.5^{\circ}$ & - & $\mathrm{O}$ & $\mathrm{O}$ \\
\hline 10 & MIROC-ESM ${ }^{*}$ & $2.8^{\circ} \times 2.8^{\circ}(\mathrm{T} 42)$ & $\mathrm{O}$ & $\mathrm{O}$ & $\mathrm{O}$ \\
\hline 11 & MPI-ESM-LR & $1.9^{\circ} \times 1.9^{\circ}(\mathrm{T} 63)$ & - & $\mathrm{O}$ & $\mathrm{O}$ \\
\hline 12 & MPI-ESM-P & $1.9^{\circ} \times 1.9^{\circ}(\mathrm{T} 63)$ & $\mathrm{O}$ & $\mathrm{O}$ & - \\
\hline 13 & MRI-CGCM3 & $1.1^{\circ} \times 1.1^{\circ}$ & $\mathrm{O}$ & $\mathrm{O}$ & - \\
\hline 14 & NorESM1-M & $1.9^{\circ} \times 2.5^{\circ}$ & - & $\mathrm{O}$ & $\mathrm{O}$ \\
\hline
\end{tabular}

levels to reduce the resolution influence in determining the $\mathrm{HC}$ edge and jet latitude.

A multimodel mean (MMM) is calculated by averaging all 9, 14, and 11 models of the LGM, PI, and ECP4.5 simulations, respectively. The MMM difference is computed by averaging the LGM-PI differences of 9 models and the ECP4.5-PI differences of 11 models.

\section{b. HC edge and jet latitude}

The HC edge is quantified as a zero-crossing latitude of the 500-hPa mass streamfunction. The 500-hPa mass streamfunction $\Psi 500$ is defined by vertically integrating the zonal-mean meridional wind $[v]$ from the top of the atmosphere to the 500-hPa pressure level as follows:

$$
\Psi 500 \equiv \frac{2 \pi a \cos \varphi}{g} \int_{0 \mathrm{hPa}}^{500 \mathrm{hPa}} \overline{[v]} d p
$$

where $a, \varphi$, and $g$ represent the radius of Earth, the latitude, and the gravitational acceleration, respectively. The square brackets and overbar denote the zonal mean and the time mean, respectively.

The eddy-driven jet is defined as the zonal wind maximum in the lower troposphere. Unlike the subtropical jet, the eddy-driven jet has a quasi-barotropic structure in the vertical. In the $\mathrm{SH}$, its latitudinal position is often defined from the zonal-mean zonal wind profile at $850 \mathrm{hPa}$. Following Adam et al. (2018), a trapezoidal interpolation method is applied to detect the latitudinal position of the maximum zonal wind from $35^{\circ}$ to $75^{\circ} \mathrm{S}$. The cubic-spline method is also tested to investigate the method sensitivity. It turns out that the jet latitude derived from the trapezoidal integration is slightly different from that estimated from the cubicspline method. However, their differences are minor and do not change the overall conclusions.
In all analyses, the $\mathrm{HC}$ edge and jet latitude are computed with annual- or seasonal-mean data and averaged over the analysis period (100 years in most cases). The statistical significance of the LGM-PI differences and the ECP4.5-PI differences is evaluated at the $95 \%$ confidence level by using the two-tailed Student's $t$ test, with a null hypothesis of equal averages in the two independent samples.

\section{Results}

Figure 1 illustrates the responses of zonally averaged temperature, mass streamfunction, and zonal wind to the LGM and ECP4.5 forcings. The temperature response to increasing greenhouse gas concentrations, which is quantified by the MMM ECP4.5-PI difference, shows a well-known pattern of strong tropical uppertropospheric warming and polar lower-tropospheric warming (Fig. 1a). A similar temperature response is also found in the MMM LGM-PI difference with a comparable amplitude but in an opposite sign (Fig. 1d), indicating a strong cooling in the tropical upper troposphere and polar lower troposphere (see also Chavaillaz et al. 2013; Son et al. 2018a). Note that the Antarctic cooling in the LGM scenario is much stronger than the Antarctic warming in the ECP4.5 scenario. This is partly due to the thickened ice sheet and enhanced polar amplification around the Antarctic Ocean in the LGM scenario.

The mass streamfunction under the PI scenario and its change in response to global warming or cooling are illustrated in Figs. 1b and 1e. The HC is characterized by a negative mass streamfunction in the tropics, indicating a counterclockwise circulation (dashed contours in Figs. $1 \mathrm{~b}$ and $1 \mathrm{e}$ ). Its outer edge is located near $30^{\circ} \mathrm{S}$. The MMM ECP4.5-PI difference shows a negative value 

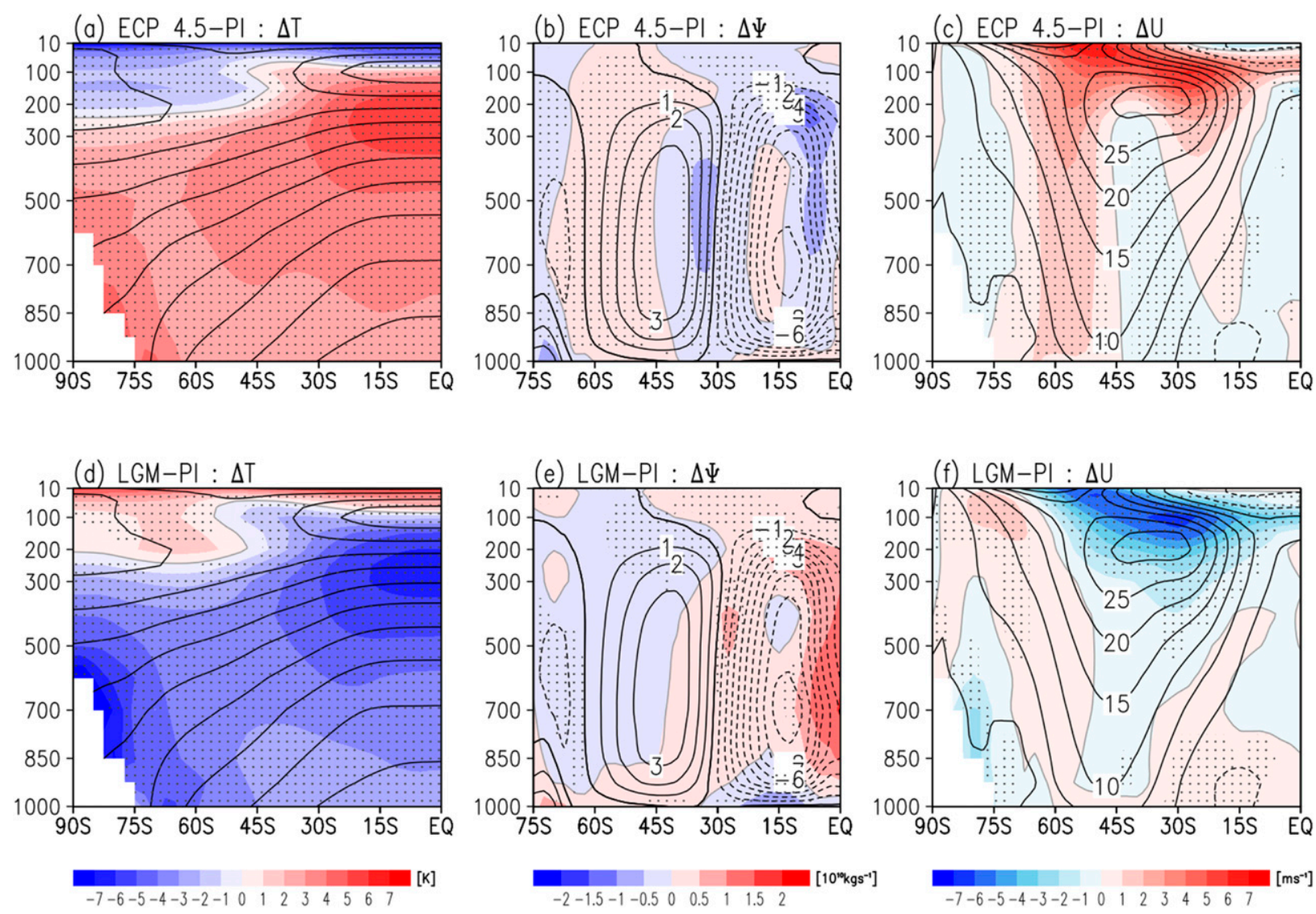

FIG. 1. Multimodel-averaged annual-mean zonal-mean (left) temperature (K), (center) mass streamfunction $\left(10^{10} \mathrm{~kg} \mathrm{~s}^{-1}\right)$, and $($ right $)$ zonal wind $\left(\mathrm{m} \mathrm{s}^{-1}\right)$ in the PI simulation (contours), with the (a)-(c) ECP4.5-PI and (d)-(f) LGM-PI differences shaded. The stippled region indicates that more than $80 \%$ of the models show the same sign. Note that the latitudinal range of (b) and (e) is different from the other panels.

(blue shading) at the HC edge. This indicates a poleward shift of the HC edge in the future climate (Fig. 1b). The opposite is also true in the MMM LGM-PI difference, indicating a relatively narrow $\mathrm{HC}$ in the LGM scenario when compared with the PI scenario (Fig. 1e). Figure 2 further shows that the $\mathrm{HC}$ edge shifts poleward from the PI scenario to the ECP4.5 scenario (Fig. 2a) but equatorward from the PI scenario to the LGM scenario (Fig. 2b). This result, revealing a poleward shift of the SH HC edge from the LGM scenario to the PI scenario and then to the ECP4.5 scenario, confirms the key finding of Son et al. (2018a).

The zonal wind shows a more complicated response to the LGM and ECP4.5 forcings (Figs. 1c,f) than the mass streamfunction. The MMM ECP4.5-PI wind difference (Fig. 1c) is generally positive on the poleward flank of the PI jet $\left(\sim 45^{\circ} S\right)$. This indicates a poleward shifted and intensified SH jet in a warm climate (Fyfe and Saenko 2006; Wilcox et al. 2012; Barnes and Polvani 2013). More importantly, most models show the same signed ECP4.5-PI wind difference near the PI jet (see the dotted region in Fig. 1c). The MMM LGM-PI zonal wind difference, however, exhibits only small values around the PI jet. On average, it is less than $1 \mathrm{~m} \mathrm{~s}^{-1}$, and this change is not systematic across the models. As hinted from the nondotted region in Fig. 1f, each model shows a different wind change around the PI jet.

A systematic poleward jet shift from the PI scenario to the ECP4.5 scenario but a nonrobust jet change from the PI scenario to the LGM scenario is further confirmed by examining each model's annual-mean circulation changes (Fig. 2). All 11 models show a poleward jet shift from the PI scenario to the ECP4.5 scenario (Fig. 2a). All models show statistically significant changes. The resulting jet shift is on average approximately $1.5^{\circ}$ latitude with two models (i.e., IPSL-CM5A-LR and IPSL-CM5A-MR) showing $3^{\circ}-4^{\circ}$ latitude shift. Such changes do not appear in the LGM-PI differences (Fig. 2b). Whereas three models (i.e., CNRM-CM5, GISS-E2-R, and IPSLCM5A-LR) show a significant equatorward jet shift, 

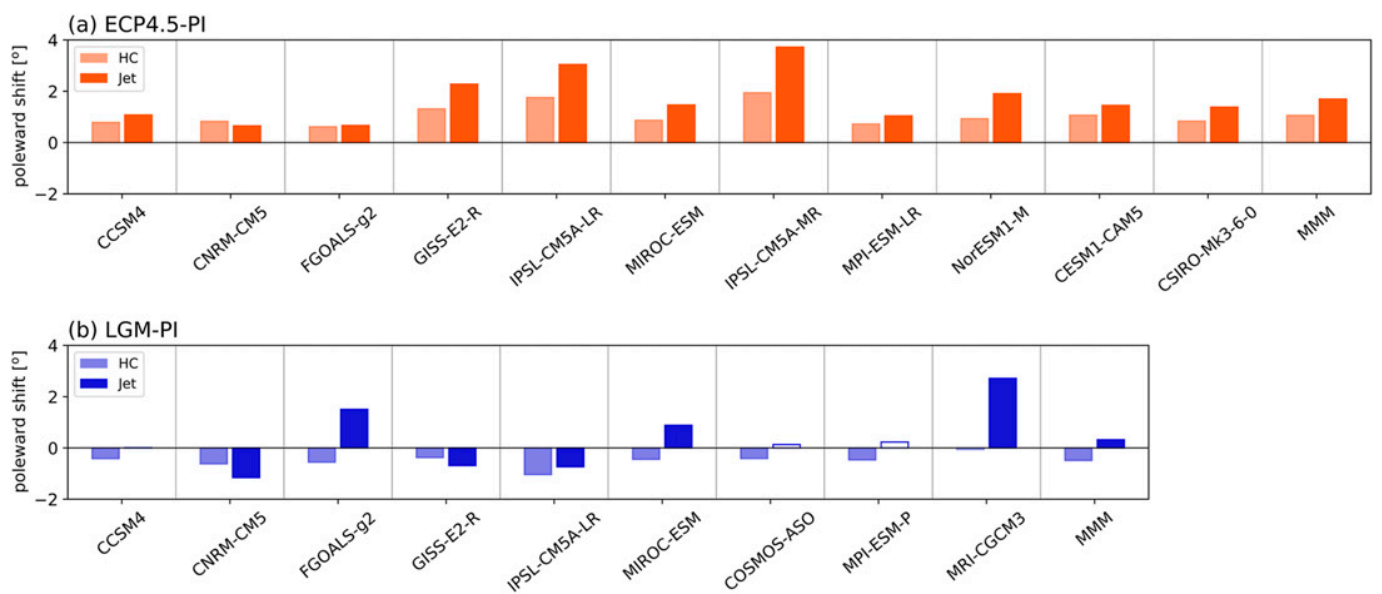

FIG. 2. The annual-mean HC edge and jet latitude changes in the (a) ECP4.5 and (b) LGM simulations in comparison with the PI simulation. The statistically significant difference at the $95 \%$ confidence level is indicated with a filled bar. Note that a positive value represents a poleward HC shift or a poleward jet shift in the SH.

three models (i.e., FGOALS-g2, MIROC-ESM, and MRI-CGCM3) show a significant poleward jet shift as in the ECP4.5-PI differences. As a result, the MMM LGM-PI difference shows a weak poleward jet shift.

The above result suggests a different $\mathrm{HC}$-jet change in the ECP4.5 scenario and in the LGM scenario. All models show a poleward shift of both the $\mathrm{HC}$ edge and jet latitude in the ECP4.5 scenario, confirming a coherent poleward shift of the SH zonal-mean circulation in a warm climate. No such relationship, however, is observed in a colder climate. In fact, six of the nine models [i.e., the CCSM4, FGOALS-g2, MIROC-ESM, the Community Earth System Models with Atmosphere, Surface, and Ocean components (COSMOS-ASO), MPI-ESM-P, and MRI-CGCM3] show that the HC edge and jet latitude changes from the PI scenario to the LGM scenario in the opposite direction (Fig. 2b).

The decoupled HC-jet change from the LGM scenario to the PI scenario (Fig. 2b) is further illustrated in Fig. 3a. The HC-jet relationship is quasi linear from the PI scenario to the ECP4.5 scenario (red), with a regression close to a 1:2 ratio as in the literature (e.g., Gerber and Son 2014). Such a relationship, however, does not appear in transitioning to a cold climate (blue). Unlike the ECP4.5-PI differences, which are all located in the top-right corner of the figure, the LGM-PI differences are spread from the top-left to bottom-left corners of the figure.

A breakdown in the HC-jet relationship in the LGM scenario is mainly observed in austral winter [JuneAugust (JJA)] (Fig. 3b). In austral summer [DecemberFebruary (DJF)], the HC-jet relationship is quasi-linear (Fig. 3c) regardless of a warm or cold climate. While the $\mathrm{HC}$ edge and jet latitude changes are linearly related in most seasons under the ECP4.5 condition (red bars in Fig. 3d), their relationship switches the sign from a positive to a negative value in austral winter with a maximum negative correlation in July-September. This result clearly indicates that the nonsystematic changes in the HC edge and jet latitude from the LGM scenario to the PI scenario are seasonally dependent, occurring only in austral winter.

\section{a. HC-jet change versus interannual covariability}

One could relate a nonsystematic long-term change, shown in Figs. 3a and 3b, with an interannual covariability of the $\mathrm{HC}$ edge and jet latitude. It is well documented that the SH HC edge and jet latitude covary on the interannual time scale, and their correlation is stronger and more statistically significant in DJF than in JJA (Kang and Polvani 2011; Waugh et al. 2018).

This is also true in all simulations analyzed in this study. The interannual HC-jet covariability is generally weak in JJA (Fig. 3e) as the annual-mean circulation change is mainly explained by JJA change (Figs. 3a-c). Most models indeed show the HC-jet interannual correlation coefficients greater than 0.6 in DJF and rather small correlation coefficients of 0.4 in JJA in the PI scenario (Fig. 3e). A strong positive interannual correlation in DJF is consistent with a coherent $\mathrm{HC}$ edge and jet latitude changes from the LGM to the PI scenario and then to ECP4.5 scenario in DJF (Fig. 3d). However, the interannual covariability in JJA, which is weak but still positive, does not match the long-term $\mathrm{HC}$-jet changes shown in Fig. 3d.

The possible relationship between the interannual covariability and long-term change of the $\mathrm{HC}$ edge and jet latitude is quantified by evaluating the interannual 

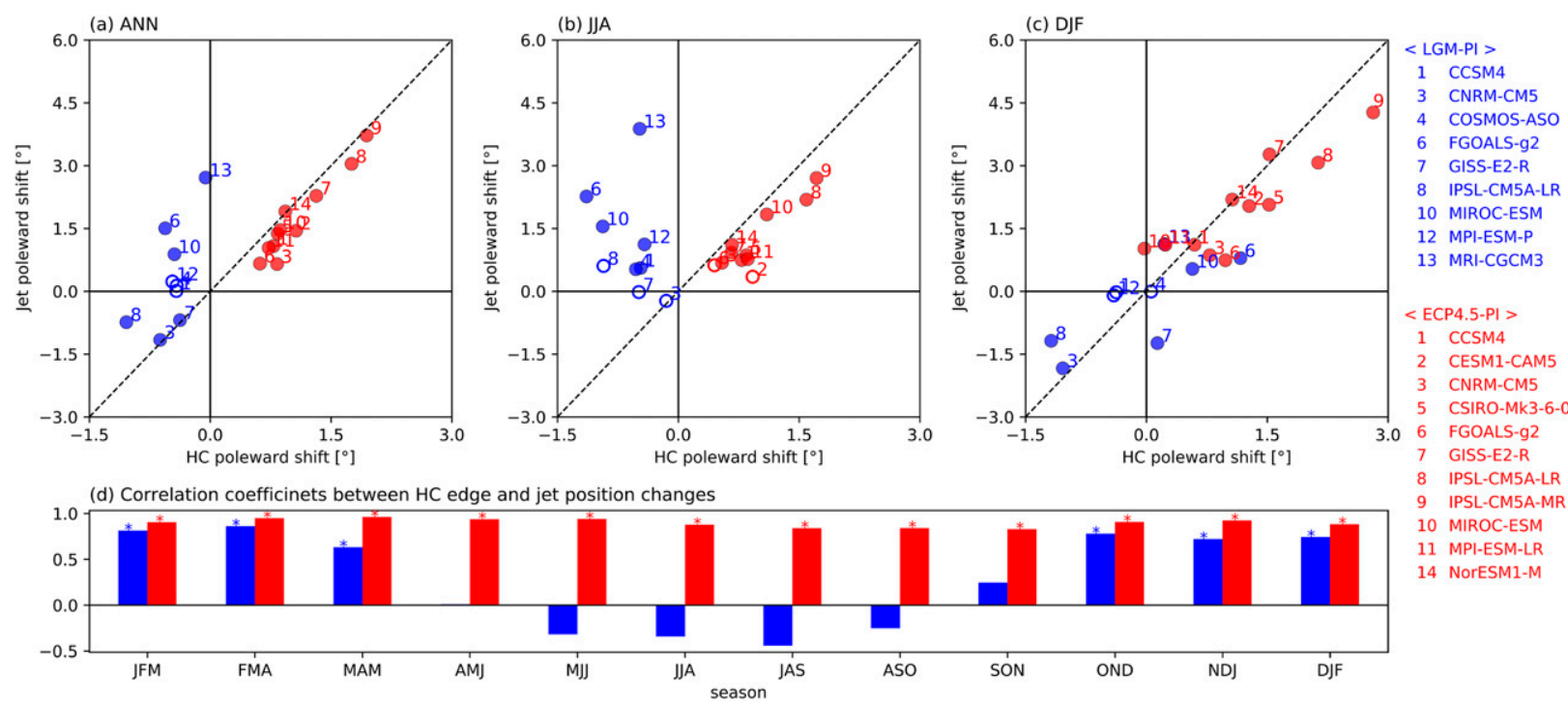

(e) Interannual correlation coefficinets between $\mathrm{HC}$ edge and jet position changes in PI simulation

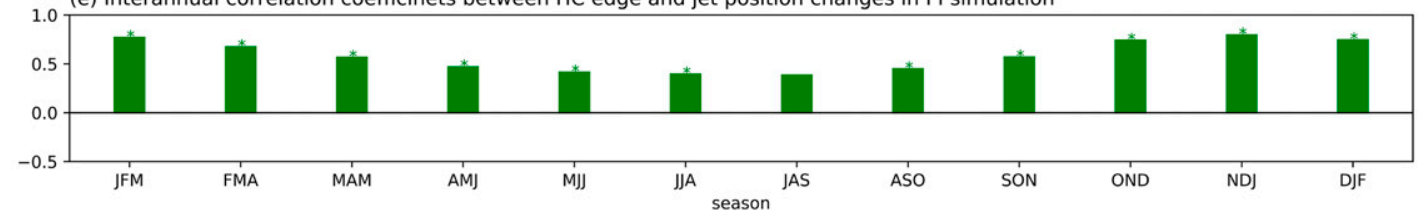

FIG. 3. Relationship between the HC edge and jet latitude changes in the LGM-PI (blue) and ECP4.5-PI (red) differences for (a) the annual mean, (b) austral winter, and (c) austral summer. The models that show statistically significant jet latitude changes are denoted with filled circles, and those with an insignificant change are denoted with an open circle. (d) Correlation coefficients between the HC edge and jet latitude changes in the LGM-PI (blue) and the ECP4.5-PI (red) differences for all seasons, with significant correlation coefficients denoted with asterisks. (e) Interannual correlation between the $\mathrm{HC}$ edge and jet latitude in the PI simulations. The correlation coefficient derived from each model is simply averaged. The asterisk indicates that more than $80 \%$ of the models have a statistically significant correlation at the $95 \%$ confidence level.

covariability ratio and long-term change ratio in Fig. 4. Here the interannual ratio is defined by the linear regression coefficient of the jet latitude to the $\mathrm{HC}$ edge across all years in the LGM or ECP4.5 simulation. The long-term ratio is defined by the jet latitude change divided by the $\mathrm{HC}$ edge change from the PI scenario to the LGM scenario or from the PI scenario to the ECP4.5 scenario. This is essentially the slope of each dot from (a) ANN

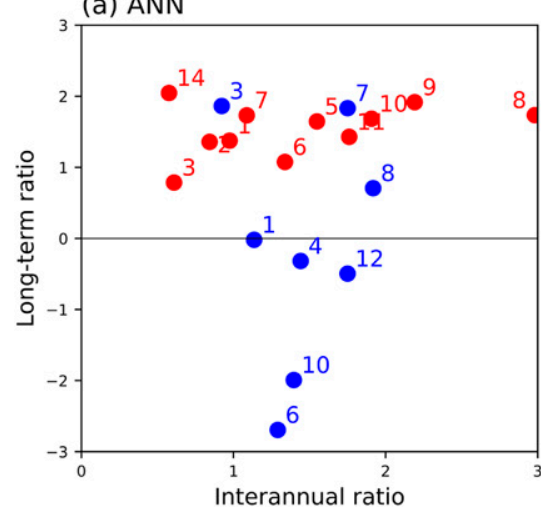

(b) JJA

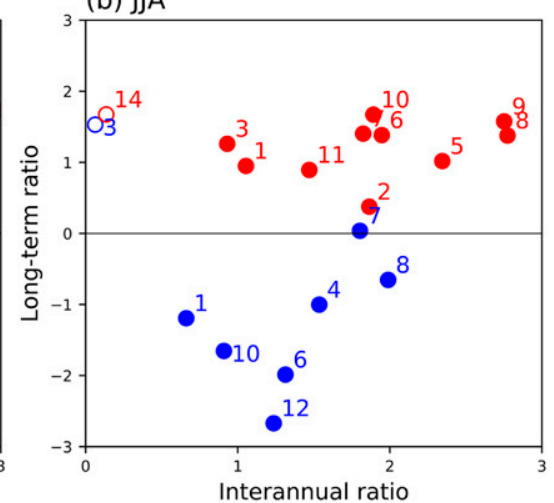

(c) DJF

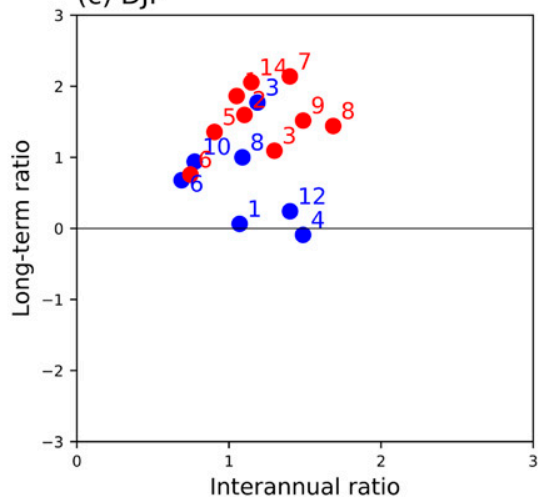

FIG. 4. Comparison between the interannual ratio and long-term ratio of HC edge to jet latitude in LGM (blue) and ECP4.5 (red) simulations for (a) the annual mean, (b) austral winter, and (c) austral summer. The long-term ratio is considered as the difference of the LGM (blue) or ECP4.5 (red) simulation from the PI simulation. The interannual ratio with a statistically significant correlation coefficient at the $95 \%$ confidence level between the $\mathrm{HC}$ edge and the jet latitude is denoted with filled circles. 
the zero in Figs. 3a-c. If the long-term ratio is greater than 1 , the jet latitude change is larger than the HC edge change. If negative, the long-term change of the jet latitude is opposite in sign to that of the HC edge (e.g., several blue dots below zero line in Figs. 4a and 4b). Since this ratio cannot be defined well when the HC edge change is close to zero or the shift of jet latitude is much greater than the $\mathrm{HC}$ edge change, those models are excluded (e.g., MRI-CGCM3 in LGM, GISS-E2-R in LGM DJF, and MIROC-ESM and MPI-ESM-LR in ECP4.5 DJF).

Figure $4 \mathrm{~b}$ shows that the interannual ratios in LGM substantially vary from 0.1 to 2.0 . This result, which indicates that the $\mathrm{HC}-\mathrm{jet}$ covariability is not robust in austral winter, is partly caused by the fact that the thermally driven $\mathrm{HC}$ becomes stronger and is only weakly influenced by midlatitude eddies in this season (e.g., Bordoni and Schneider 2010). However, all simulations still show positive interannual ratios in the LGM scenario. This differs from the long-term ratios that are even negative in some LGM models (blue dots in Fig. 4b). This result clearly suggests that the long-term trend and interannual variability are not necessarily controlled by the same dynamic processes.

The HC edge and jet latitude covary remarkably well in DJF (Fig. 4c). The interannual ratio is on average 1.2 for the LGM scenario, 1.3 for the PI scenario, and 1.2 for the ECP4.5 scenario, indicating that the jet latitude change is slightly larger than the HC edge change. This value is similar to the one in the reanalysis (about 1.1). The interannual ratios, which widely spread from near 0.7 to 1.7 , are partly related to the long-term ratios. This is especially true in the ECP4.5 scenario. The interannual ratios in the ECP4.5 scenario are related to the long-term ratios in the ECP4.5-PI differences (red dots in Fig. 4c). This may imply that both long-term change and interannual covariability are mediated by the same dynamical process. Such a linear relationship, however, does not appear in the LGM-PI differences (blue dots in Fig. 4c). This result again suggests that the long-term circulation changes cannot be simply explained by internal dynamics (e.g., Li et al. 2015).

\section{b. Model mean bias}

The HC-jet decoupling in the LGM-PI difference may be associated with model mean biases and/or thermal forcings that are different from the ECP4.5-PI difference. Since the decoupling is found only in JJA, all analyses below are focused on JJA circulation changes.

The jet response to external forcing is influenced by the background flow. For instance, Son and Lee (2005) showed that a poleward jet shift in response to the polar cooling becomes stronger when tropical driving is relatively weak. This could result in the eddy-driven jet becoming separated from the subtropical jet. Such jet separation is observed in the MRI-CGCM3 LGM simulation (Fig. 5i). The eddy-driven jet (maximum wind at $850 \mathrm{hPa}$ ) is clearly separated from the subtropical jet (maximum wind at $300 \mathrm{hPa}$ ). This jet structure change may partly explain a significant poleward jet shift from the PI scenario to the LGM scenario in this model (Figs. 3b and 5i).

A significant poleward jet shift from the PI scenario to the LGM scenario in FGOALS-g2 could also be caused by the latitudinal jet structure. As shown in Fig. 5d, this model shows an almost flat zonal wind profile at $850 \mathrm{hPa}$ in the LGM condition. A similar flattening is also observed in GISS-E2-R. Such flattening of the midlatitude jet, which is not observed in the ECP4.5 scenario (see Fig. S1 in the online supplemental material), could lead to a large jet latitude change with a slight wind change.

It should be stated that the majority of models fail to reproduce the climatological jet latitude in the observations. In JJA, the jet in the Japanese 55-year Reanalysis (JRA-55; Kobayashi et al. 2015) is located at $49^{\circ} \mathrm{S}$. Among the nine models examined in Fig. 5, only three models, CCSM4, CNRM-CM5, and MRI-CGCM3, reproduce such a high-latitude jet under the PI condition (cf. the black and gray lines in Fig. 5). All other models show the jet biased to lower latitudes. Three models (i.e., FGOALS-G2, IPSL-CM5A-LR, and MIROCESM) display the jet at even $42^{\circ}$ or $43^{\circ} \mathrm{S}$ in PI condition, about $7^{\circ}$ equatorward from the jet in the modern reanalysis data. This bias could affect the jet latitude response to the Antarctic cooling in the LGM condition. Previous studies have indicated that the models with a lower-latitude jet tend to have a larger jet latitude response to climate change in austral winter (Kidston and Gerber 2010; Simpson and Polvani 2016). This may suggest that a significant poleward shift in the austral winter jet in FGOALS-g2 (Fig. 5d) and MIROC-ESM (Fig. $5 \mathrm{~g}$ ) is partly due to the model mean bias. However, it is found that the jet latitude change is not directly correlated with the climatological jet position in each model (not shown).

\section{c. Tropical versus polar thermal drivings}

It is well documented that both the HC edge and jet latitude are controlled by eddy momentum fluxes (Walker and Schneider 2006; Caballero 2007; Lu et al. 2008; Son et al. 2018b). Since eddy fluxes are sensitive to thermal forcings, the zonal-mean circulation changes have often been related to meridional and/or vertical temperature gradient changes. Under global warming, the tropical upper-tropospheric warming acts to increase static stability in the subtropics and an equator-to-pole 


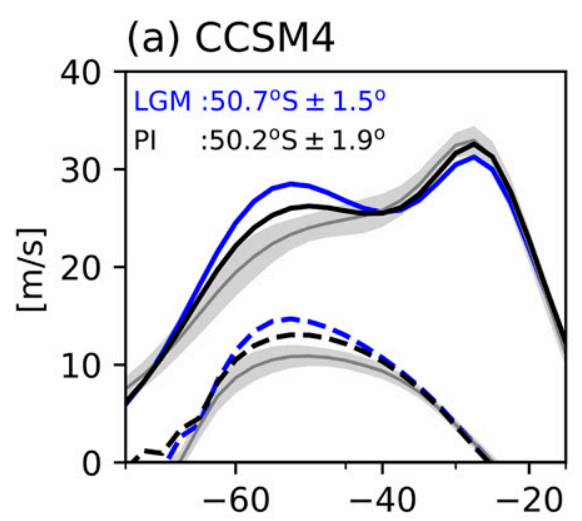

(b) CNRM-CM5

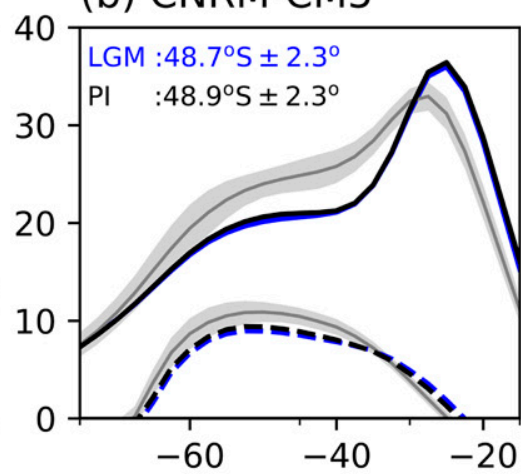

(e) GISS-E2-R

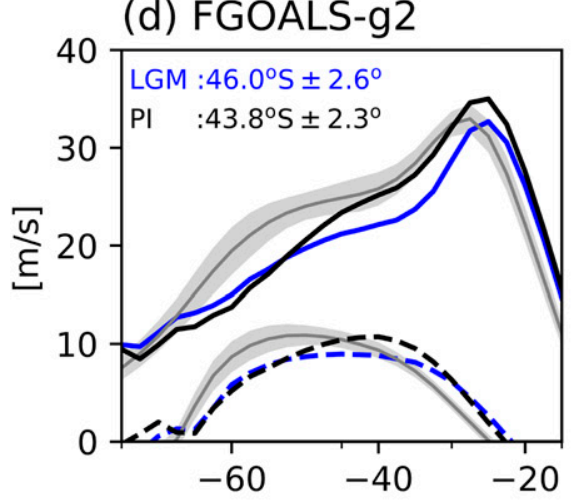

(g) MIROC-ESM

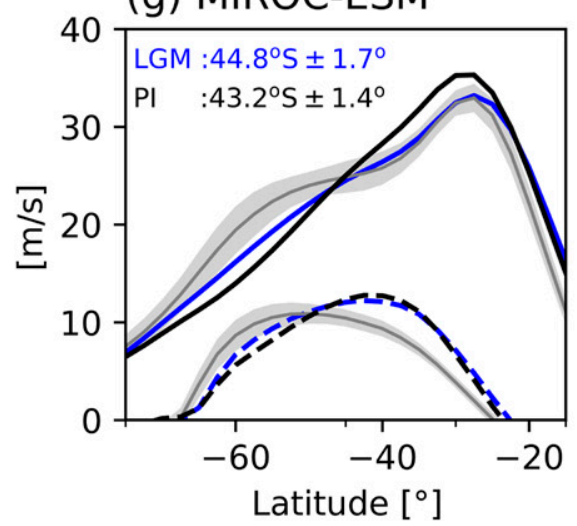

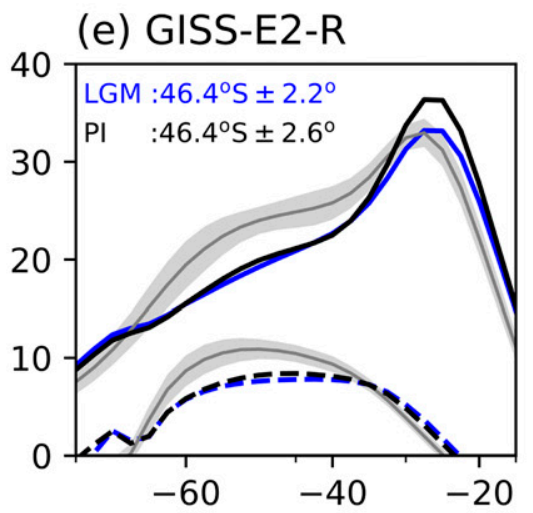

(h) MPI-ESM-P

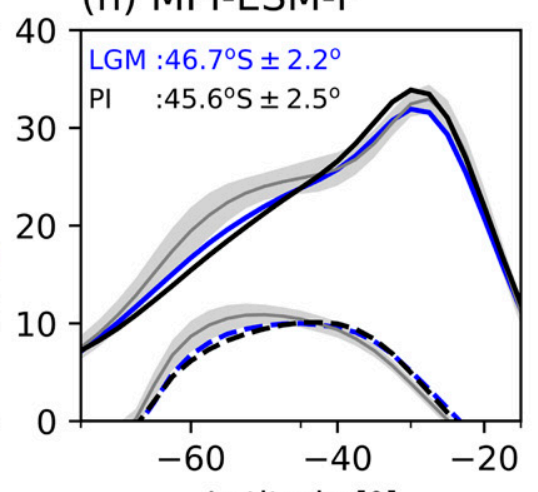

Latitude $\left[{ }^{\circ}\right]$

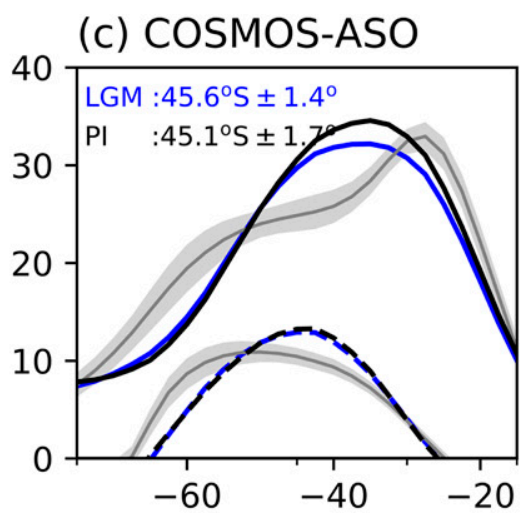

(f) IPSL-CM5A-LR

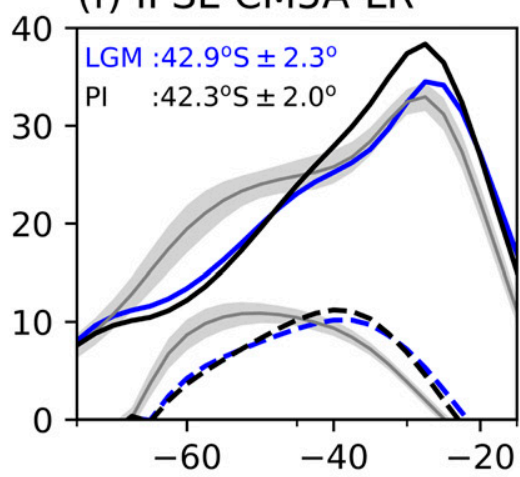

(i) MRI-CGCM3

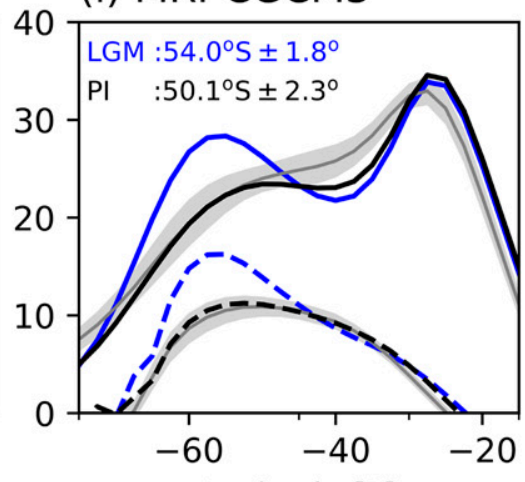

Latitude $\left[{ }^{\circ}\right]$

FIG. 5. The austral winter (JJA) zonal-mean zonal wind at 300 (solid lines) and 850 (dashed lines) hPa in the LGM (blue) and PI (black) simulations. The reference wind profile from JRA-55 is also shown in gray, with 1 standard deviation on the interannual time scale indicated by the shading. The position of the eddy-driven jet and its 1 standard deviation are indicated in the top-left corner of each panel.

temperature gradient in the upper troposphere (e.g., Fig. 1a). This tends to drive a HC expansion and a poleward jet shift in both idealized and comprehensive general circulation model simulations (e.g., Butler et al. 2010; Gerber and Son 2014). In contrast, the polar amplification could cancel such circulation changes by reducing the equator-to-pole temperature gradient near the surface (e.g., Barnes and Polvani 2015).
From Figs. 1a and 1d, the LGM and ECP4.5 thermal forcings are quantified by the tropical temperature changes at $250 \mathrm{hPa}$ averaged over $0^{\circ}-30^{\circ} \mathrm{S}\left(\Delta T_{\text {trop,250 }}\right)$ and the Antarctic near-surface temperature changes at $925 \mathrm{hPa}$ averaged over $55^{\circ}-75^{\circ} \mathrm{S}\left(\Delta T_{\text {pole, } 925}\right)$, with respect to the PI condition. These temperature indices are first compared with the latitudinal jet shifts. It turns out that the jet latitude change is not directly related to each index (Fig. 6) or their linear combination (not shown). 

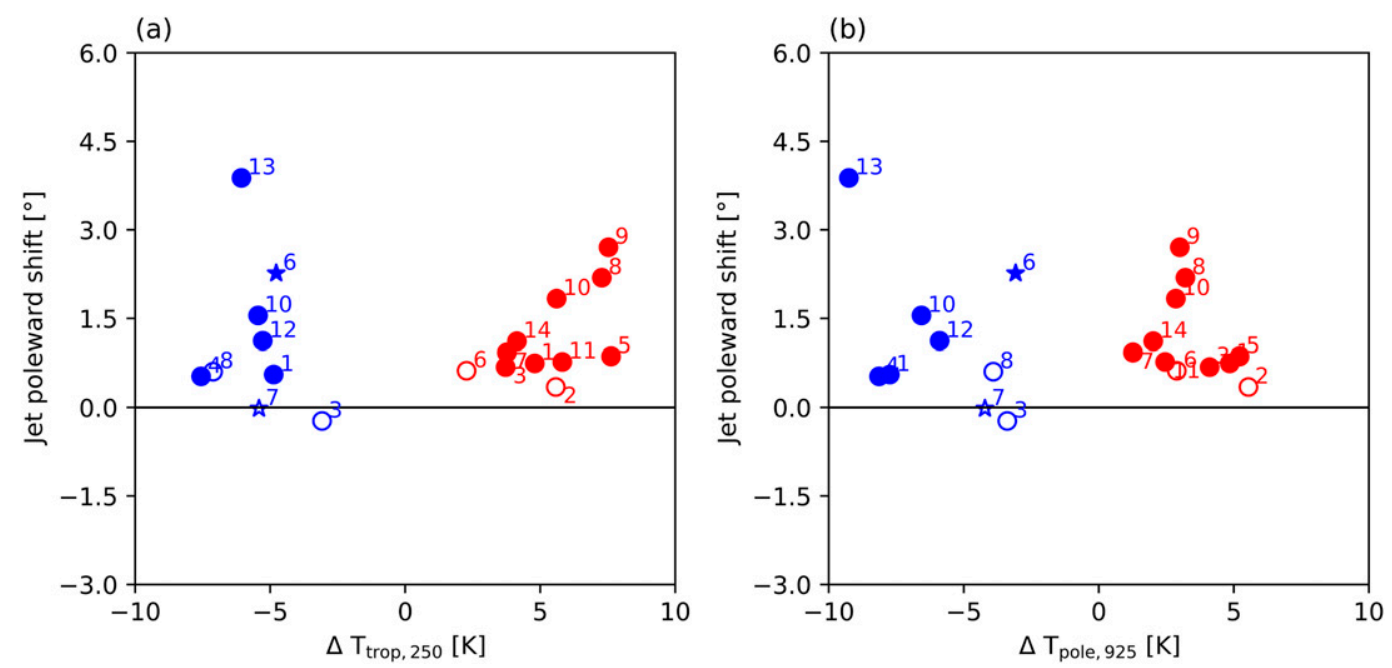

FIG. 6. The relationship of jet latitude change to (a) $\Delta T_{\text {trop }, 250}$ and (b) $\Delta T_{\text {pole, } 925}$ in the LGM-PI (blue) and ECP4.5-PI (red) differences in austral winter (JJA). The stars denote the models with a flattened eddy-driven jet in the LGM simulations. The filled circles indicate the models that have statistically significant jet latitude changes as in Fig. 3.

The relative importance of tropical and polar temperature changes in the zonal-mean circulation change is qualitatively evaluated in Fig. 7 for both the LGM and ECP4.5 simulations. It is apparent from Figs. $7 \mathrm{a}$ and $7 \mathrm{~b}$ that most models have a comparable or greater tropical warming than the Antarctic warming in the ECP4.5 scenario (values around or above the diagonal axis). This result suggests that a coherent poleward shift in the $\mathrm{HC}$ edge and jet latitude from the PI scenario to the ECP4.5 scenario is likely related to the greater impact of the tropical upper-tropospheric warming than that of the high-latitude near-surface warming. This result, implying upper-tropospheric driving rather than lower-tropospheric driving, is consistent with previous findings (e.g., Lu et al. 2008; Gerber and Son 2014; Grise and Polvani 2016).

The upper-tropospheric driving, however, is unlikely to hold in the LGM scenario (Figs. 7c,d). As discussed in Rojas (2013) and Chavaillaz et al. (2013), the Antarctic temperature response $\left(\Delta T_{\text {pole, } 925}\right)$ has a larger intermodel spread in the LGM scenario than in the ECP4.5 scenario. In DJF, the tropical upper-tropospheric cooling in the LGM scenario is still stronger than the Antarctic cooling (values below the diagonal axis in Fig. 7d), as in the ECP4.5 scenario. However, this is not the case in LGM JJA. Only three models (FGOALS-g2, GISS-E2$\mathrm{R}$, and IPSL-CM5A-LR) show a stronger tropical cooling than the polar cooling (Fig. 7c), while others show a comparable or weaker tropical cooling than the polar cooling. Among them, five models (CCSM4, COSMOSASO, MIRO-ESM, MPI-ESM-P, and MRI-CGCM3) show the near-surface polar cooling greater than $-6 \mathrm{~K}$. Such a large polar temperature change does not appear in the ECP4.5 scenario. None of 11 ECP4.5 simulations show the polar warming greater than $6 \mathrm{~K}$ (Figs. 7a,b).

This difference, that is, strong JJA polar cooling in the LGM simulation, may explain the decoupled HC-jet change in the LGM condition. Although the JJA jet changes are not linearly related to the near-surface polar temperature changes, all the models that have a stronger polar cooling than the tropical cooling show a poleward jet shift from the PI scenario to the LGM scenario. This, however, cannot be generalized. There are two exceptional models that show a poleward jet shift under a somewhat weaker polar cooling condition. These models have a polar cooling weaker than the tropical cooling in JJA. Note that although FGOALS-g2 (6 in Fig. 7c) exhibits a large jet latitude change of approximately $2.5^{\circ}$, this change may not be physically meaningful because the jet is not well defined in this model (see section $3 b$ ).

\section{d. Idealized model experiments}

The relative importance of the near-surface polar cooling and upper-tropospheric tropical cooling in the SH circulation change is further explored by conducting a set of idealized model simulations. As in Son and Lee (2005) and Martineau et al. (2018), a dynamic core is utilized for a parameter sweep experiment. Specifically, a Geophysical Fluid Dynamics Laboratory (GFDL) dynamic core, which has been widely used in the literature (e.g., Martineau et al. 2018), is integrated for 1500 days with a T85L40 resolution. Only the last 1000 days, discarding the first 500 days for spin up, are analyzed. This model is basically forced by relaxing temperature to the equilibrium temperature profile of 
(a) ECP4.5-PI (JJA)

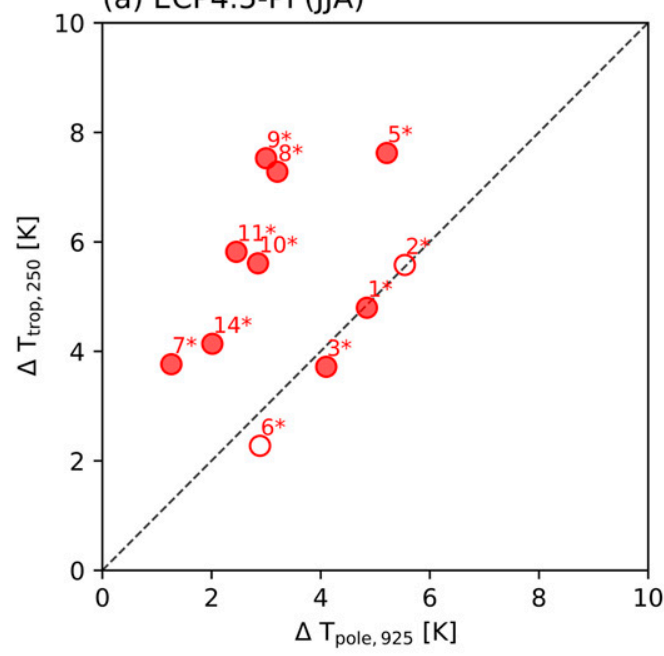

(c) LGM-PI (JJA)

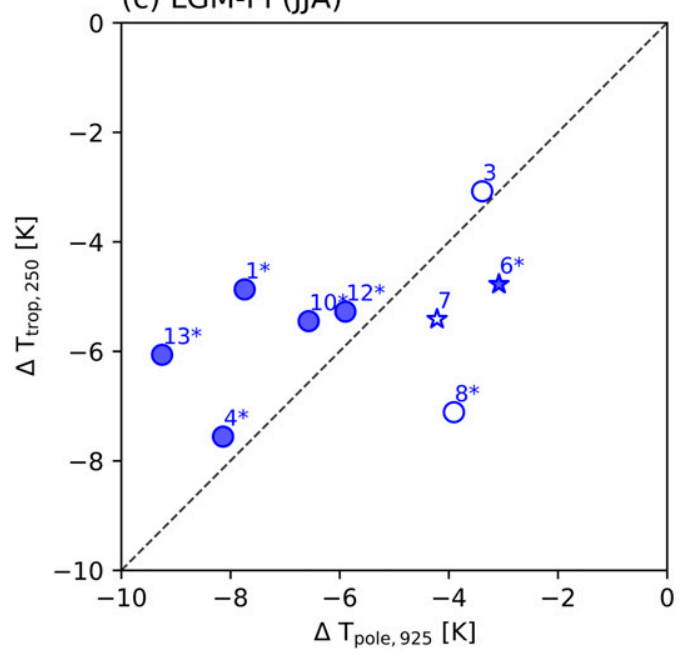

(b) ECP4.5-PI (DJF)

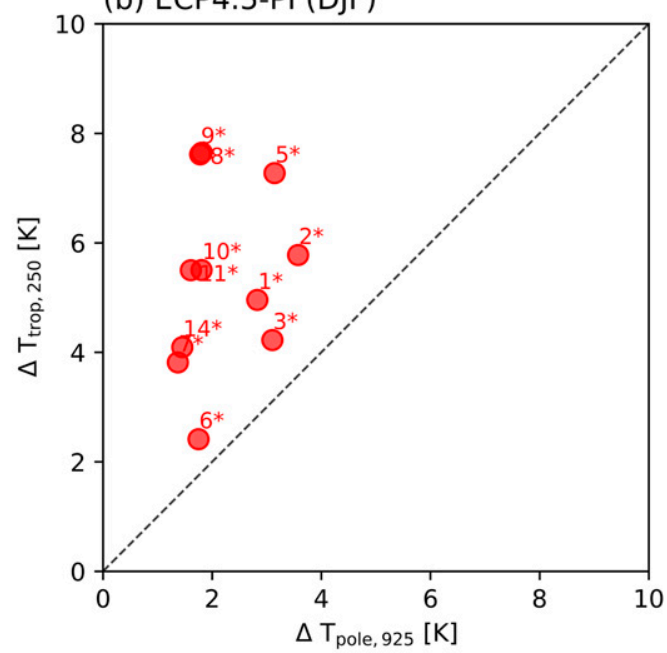

(d) LGM-PI (DJF)

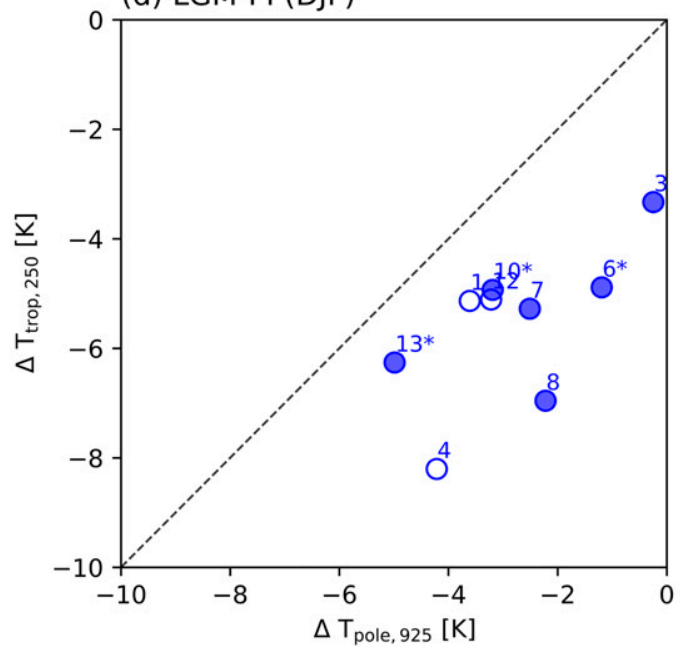

FIG. 7. Polar temperature changes at $925 \mathrm{hPa}\left(\Delta T_{\text {pole, } 925}\right)$ and tropical temperature changes at $250 \mathrm{hPa}\left(\Delta T_{\text {trop,250 }}\right)$ in austral (left) winter and (right) summer for the (a),(b) ECP4.5-PI differences (c),(d) LGM-PI differences. The model that shows a statistically significant jet latitude change is denoted with a filled circle, and that with an insignificant change is denoted with an open circle as in Figs. 3 and 6. The asterisk indicates the model showing a poleward jet shift.

Held and Suarez (1994) with a thermal equator at $6^{\circ} \mathrm{N}$ mimicking the austral winter condition (black contour in Fig. 8a). The control run is performed without any additional forcing. The two sets of perturbation runs are carried out with additional thermal forcings to mimic the LGM condition. In the perturbation runs, the external forcings are imposed in the tropical upper troposphere, $q_{\text {trop }}$, and in the polar surface, $q_{\text {pole }}$, as shaded in Fig. 8 a.

The two sets of perturbation runs are conducted with a moderate tropical cooling of $q_{\text {trop }}=-0.5 \mathrm{~K} \mathrm{day}^{-1}$ (triangles with " $\mathrm{M}$ " in Figs. $8 \mathrm{~b}$ and $8 \mathrm{c}$ ) or a relatively strong tropical cooling of $q_{\text {trop }}=-0.7 \mathrm{~K} \mathrm{day}^{-1}$ (circles with " $\mathrm{S}$ " in Figs. $8 \mathrm{~b}$ and $8 \mathrm{c}$ ). Both experiments consist of six simulations with varying $q_{\text {pole }}$ from -3.2 to $-1.2 \mathrm{~K}$ day $^{-1}$ in $0.4 \mathrm{~K} \mathrm{day}^{-1}$ intervals. Here M6/S6 corresponds to the most polar cooling, and M1/S1 corresponds to the least polar cooling. The temperature response to these thermal forcings is summarized in Fig. 8b in terms of $\Delta T_{\text {trop }, 250}$ and $\Delta T_{\text {pole, } 850}$. The two $q_{\text {trop }}$ forcings lead to $\Delta T_{\text {trop }, 250}$ of about -5.5 and $-6.5 \mathrm{~K}$, which are comparable to the LGM-PI differences (Fig. 7c). The six $q_{\text {pole }}$ forcings result in $\Delta T_{\text {pole }, 850}$ from -3.0 to $-8.0 \mathrm{~K}$. Again, these values are comparable to the LGM-PI differences (Fig. 7c).

Figure $8 \mathrm{c}$ shows that the polar cooling indeed plays a crucial role in determining the $\mathrm{HC}-$ jet decoupling in the LGM-like condition. Although the $\mathrm{HC}$ edge shifts equatorward in all simulations, the jet latitude shifts either equatorward or poleward depending on the 

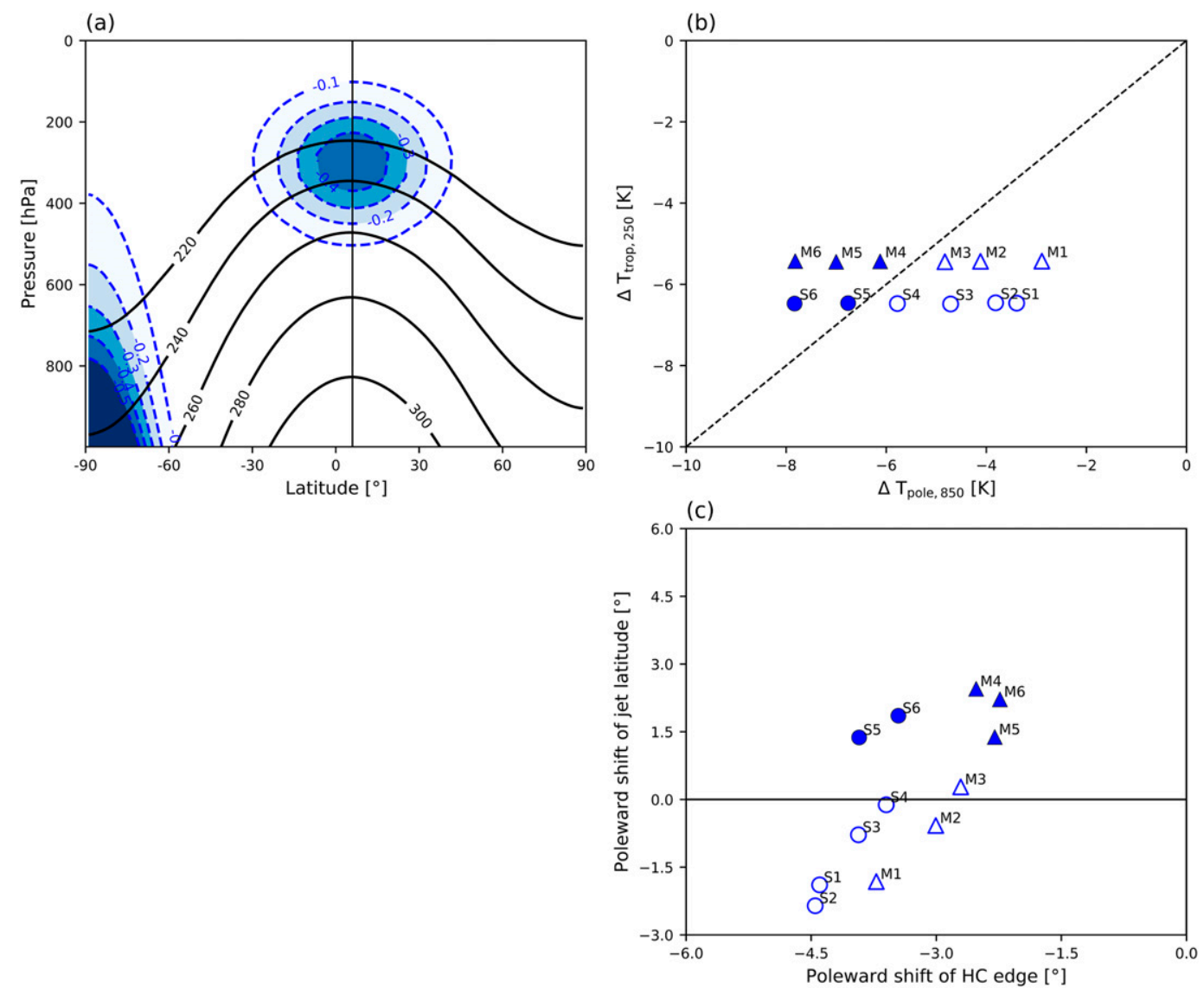

FIG. 8. (a) The equilibrium temperature profile (black contours) and external thermal forcings (shading) for M1 run with $q_{\text {trop }}=-0.5 \mathrm{~K} \mathrm{day}^{-1}$ and $q_{\text {pole }}=-1.2 \mathrm{~K} \mathrm{day}^{-1}$, (b) $\Delta T_{\text {trop }, 250}$ and $\Delta T_{\text {pole, } 850}$ in all equilibrium simulations, and (c) the $\mathrm{HC}$ edge and jet latitude changes from the control run. In (a), contour and shading intervals are $20 \mathrm{~K}$ and $0.1 \mathrm{~K} \mathrm{day}^{-1}$, respectively. In (b) and (c), a larger number next to the symbol indicates a stronger polar cooling of each simulation. The simulations in which the polar cooling is stronger than the tropical cooling are denoted with filled symbols.

strength of polar cooling. When the polar cooling is stronger than $-6 \mathrm{~K}$, the jet tends to shift poleward (e.g., M4-M6 and S5-S6 runs in Fig. 8b). Otherwise, the jet does not change much or moves equatorward.

This result supports our hypothesis, that is, the HC-jet decoupling by strong polar amplification. However, to generalize this finding, a wider range of parameter sweep study (e.g., $q_{\text {trop }}$ from 0.1 to $0.9 \mathrm{~K} \mathrm{day}^{-1}$ with $0.1 \mathrm{~K} \mathrm{day}^{-1}$ intervals) is required. A longer simulation would also be needed. Such an expansion of idealized model experiments will be conducted in a future study. The detailed dynamical mechanism(s) of the HC-jet decoupling will also be documented in a future study.

\section{Summary and discussion}

This study examines the relationship between the $\mathrm{HC}$ edge and eddy-driven jet latitude in the $\mathrm{SH}$ from cold to warm climates. All analyses are conducted by comparing the LGM and ECP4.5 scenario simulations against the PI simulations archived for PMIP3 and CMIP5. Consistent with previous studies, the annualmean $\mathrm{HC}$ edge and jet latitude move together toward higher latitudes under the ECP4.5 condition. Such a systematic change, however, does not appear in the LGM simulations. While the annual-mean HC edge shifts equatorward in all LGM simulations, the annualmean jet shifts either equatorward or poleward depending on models. Only three of nine models show a coherent equatorward shift of the annual-mean HC edge and jet latitude from the PI scenario to the LGM scenario. Other models show no relationship or even opposite jet changes from those of the $\mathrm{HC}$ edge. These nonsystematic changes are mainly caused by the intermodel differences in the jet latitude changes in austral winter (JJA). The ratio of the jet latitude change to the HC edge change under the LGM condition is independent of interannual HC-jet covariability, indicating that 
the decoupled circulation changes in LGM JJA cannot be simply explained by intrinsic $\mathrm{HC}$-jet dynamics.

It is not clear why the $\mathrm{HC}$ edge and jet latitude respond differently in the LGM condition. Although the jet latitude change could be influenced by the jet structure, no clear relationship is found. The midlatitude jet that becomes flat in several LGM simulations instead introduces an uncertainty in the jet latitude detection, making the jet latitude less physically meaningful. We speculate that a strong near-surface polar cooling in LGM JJA, which is comparable to or even stronger than a tropical upper-tropospheric cooling, is likely responsible for the HC-jet decoupling. Most models with a poleward jet shift in the LGM condition exhibit the near-surface polar cooling that is stronger than the upper-tropospheric tropical cooling. A series of idealized model experiments indeed show that the jet tends to shift poleward when the near-surface polar cooling is stronger than the upper-tropospheric tropical cooling. However, regardless of the amplitude of the thermal forcings, the HC edge shifts equatorward under the LGM-like condition. The detailed dynamical processes that determine the HC-jet decoupling will be explained in a future study.

A series of studies have shown that the upper-tropospheric temperature gradient change is more closely related to the zonal-mean circulation change in the present and warm climates (Gerber and Son 2014; Vallis et al. 2015; Grise and Polvani 2016; Choi et al. 2019). Although not conclusive, our study suggests that the lowertropospheric temperature gradient change could be more important than the upper-tropospheric temperature gradient change if the polar temperature change is comparable to or even stronger than the tropical temperature change in a cold climate. With more models available from the PMIP4 and CMIP6, the relative importance of upper-tropospheric versus lower-tropospheric temperature gradient changes in zonal-mean circulation changes could be quantitatively evaluated.

Acknowledgments. Comments from the anonymous reviewers of this work are greatly appreciated. This work was supported by the National Research Foun dation of Korea (NRF) grant funded by the South Korean government (Ministry of Science and ICT) (2017R1E1A1A01074889) and NRF-2018R1A5A1024958.

\section{REFERENCES}

Adam, O., and Coauthors, 2018: The TropD software package (v1): Standardized methods for calculating tropical-width diagnostics. Geosci. Model Dev., 11, 4339-4357, https://doi.org/ 10.5194/gmd-11-4339-2018.

Barnes, E. A., and L. M. Polvani, 2013: Response of the midlatitude jets, and of their variability, to increased greenhouse gases in the CMIP5 models. J. Climate, 26, 7117-7135, https://doi.org/ 10.1175/JCLI-D-12-00536.1.

- and - 2015: CMIP5 projections of Arctic amplification, of the North American/North Atlantic circulation, and of their relationship. J. Climate, 28, 5254-5271, https://doi.org/10.1175/ JCLI-D-14-00589.1.

Bordoni, S., and T. Schneider, 2010: Regime transitions of steady and time-dependent Hadley circulations: Comparison of axisymmetric and eddy-permitting simulations. J. Atmos. Sci., 67, 1643-1654, https://doi.org/10.1175/ 2009JAS3294.1.

Braconnot, P., S. P. Harrison, M. Kageyama, P. J. Bartlein, V. Masson-Delmotte, A. Abe-Ouchi, B. Otto-Bliesner, and Y. Zhao, 2012: Evaluation of climate models using palaeoclimatic data. Nat. Climate Change, 2, 417-424, https:// doi.org/10.1038/nclimate1456.

Butler, A. H., D. W. Thompson, and R. Heikes, 2010: The steady-state atmospheric circulation response to climate change-like thermal forcings in a simple general circulation model. J. Climate, 23, 3474-3496, https://doi.org/10.1175/ 2010JCLI3228.1.

Caballero, R., 2007: Role of eddies in the interannual variability of Hadley cell strength. Geophys. Res. Lett., 34, L22705, https:// doi.org/10.1029/2007GL030971.

Ceppi, P., and D. L. Hartmann, 2013: On the speed of the eddydriven jet and the width of the Hadley cell in the Southern Hemisphere. J. Climate, 26, 3450-3465, https://doi.org/ 10.1175/JCLI-D-12-00414.1.

Chavaillaz, Y., F. Codron, and M. Kageyama, 2013: Southern westerlies in LGM and future (RCP4.5) climates. Climate Past, 9, 517-524, https://doi.org/10.5194/cp-9-517-2013.

Choi, J., S.-W. Son, J. Lu, and S. K. Min, 2014: Further observational evidence of Hadley cell widening in the Southern Hemisphere. Geophys. Res. Lett., 41, 2590-2597, https:// doi.org/10.1002/2014GL059426.

,$- \ldots$, and R. Park, 2019: Aerosol versus greenhouse gas impacts on Southern Hemisphere general circulation changes. Climate Dyn., 52, 4127-4142, https://doi.org/10.1007/s00382018-4370-5.

D'Agostino, R., P. Lionello, O. Adam, and T. Schneider, 2017: Factors controlling Hadley circulation changes from the Last Glacial Maximum to the end of the 21st century. Geophys. Res. Lett., 44, 8585-8591, https://doi.org/10.1002/ $2017 \mathrm{~g} 1074533$.

Fyfe, J. C., and O. A. Saenko, 2006: Simulated changes in the extratropical Southern Hemisphere winds and currents. Geophys. Res. Lett., 33, L06701, https://doi.org/10.1029/ 2005 GL025332.

Gerber, P. E., and S.-W. Son, 2014: Quantifying the summertime response of the austral jet stream and Hadley cell to stratospheric ozone and greenhouse gases. J. Climate, 27, 5538-5559, https:// doi.org/10.1175/JCLI-D-13-00539.1.

Grise, K. M., and L. M. Polvani, 2016: Is climate sensitivity related to dynamical sensitivity? J. Geophys. Res. Atmos., 121, 51595176, https://doi.org/10.1002/2015JD024687.

—_, and Coauthors, 2019: Recent tropical expansion: Natural variability or forced response? J. Climate, 32, 1551-1571, https://doi.org/10.1175/JCLI-D-18-0444.1.

Harrison, S. P., P. J. Bartlein, K. Izumi, G. Li, J. Annan, J. Hargreaves, P. Braconnot, and M. Kageyama, 2015: Evaluation of CMIP5 palaeo-simulations to improve climate projections. Nat. Climate Change, 5, 735-743, https://doi.org/ 10.1038/nclimate2649. 
Held, I. M., and M. J. Suarez, 1994: A proposal for the intercomparison of the dynamical cores of atmospheric general circulation models. Bull. Amer. Meteor. Soc., 75, 1825-1830, https:// doi.org/10.1175/1520-0477(1994)075<1825:APFTIO > 2.0.CO;2.

$\mathrm{Hu}, \mathrm{Y}$. , and Q. Fu, 2007: Observed poleward expansion of the Hadley circulation since 1979. Atmos. Chem. Phys., 7, 5229 5236, https://doi.org/10.5194/acp-7-5229-2007.

- L. Tao, and J. Liu, 2013: Poleward expansion of the Hadley circulation in CMIP5 simulations. Adv. Atmos. Sci., 30, 790795, https://doi.org/10.1007/s00376-012-2187-4.

Kang, S. M., and L. M. Polvani, 2011: The interannual relationship between the latitude of the eddy-driven jet and the edge of the Hadley cell. J. Climate, 24, 563-568, https://doi.org/10.1175/ 2010JCLI4077.1.

Kidston, J., and E. P. Gerber, 2010: Intermodel variability of the poleward shift of the austral jet stream in the CMIP3 integrations linked to biases in 20th century climatology. Geophys. Res. Lett., 37, L09708, https://doi.org/10.1029/ 2010GL042873.

Kobayashi, S., and Coauthors, 2015: The JRA-55 reanalysis: General specifications and basic characteristics. J. Meteor. Soc. Japan, 93, 5-48, https://doi.org/10.2151/jmsj.2015-001.

Lee, S. H., P. D. Williams, and T. H. Frame, 2019: Increased shear in the North Atlantic upper-level jet stream over the past four decades. Nature, 572, 639-642, https://doi.org/10.1038/s41586019-1465-z.

Li, C., B. Stevens, and J. Marotzke, 2015: Eurasian winter cooling in the warming hiatus of 1998-2012. Geophys. Res. Lett., 42, 8131-8139, https://doi.org/10.1002/2015GL065327.

Lu, J., G. Chen, and D. M. Frierson, 2008: Response of the zonal mean atmospheric circulation to El Niño versus global warming. J. Climate, 21, 5835-5851, https://doi.org/10.1175/ 2008JCLI2200.1.

Lucas, C., B. Timbal, and H. Nguyen, 2014: The expanding tropics: A critical assessment of the observational and modeling studies. Wiley Interdiscip. Rev.: Climate Change, 5, 89-112, https://doi.org/10.1002/wcc.251.

Mantsis, D. F., S. Sherwood, R. Allen, and L. Shi, 2017: Natural variations of tropical width and recent trends. Geophys. Res. Lett., 44, 3825-3832, https://doi.org/10.1002/2016GL072097.

Marshall, J., and K. Speer, 2012: Closure of the meridional overturning circulation through Southern Ocean upwelling. Nat. Geosci., 5, 171-180, https://doi.org/10.1038/ngeo1391.

Martineau, P., G. Chen, S.-W. Son, and J. Kim, 2018: Lowerstratospheric control of the frequency of sudden stratospheric warming events. J. Geophys. Res. Atmos., 123, 3051-3070 https://doi.org/10.1002/2017JD027648.
Rojas, M., 2013: Sensitivity of Southern Hemisphere circulation to LGM and $4 \times \mathrm{CO}_{2}$ climates. Geophys. Res. Lett., 40, 965-970, https://doi.org/10.1002/grl.50195.

Seidel, D. J., Q. Fu, W. J. Randel, and T. J. Reichler, 2008: Widening of the tropical belt in a changing climate. Nat. Geosci., 1, 21-24, https://doi.org/10.1038/ngeo.2007.38.

Simpson, I. R., and L. M. Polvani, 2016: Revisiting the relationship between jet position, forced response and annular mode variability in the southern midlatitudes. Geophys. Res. Lett., 43, 2896-2903, https://doi.org/10.1002/2016GL067989.

Son, S.-W., and S. Lee, 2005: The response of westerly jets to thermal driving in a primitive equation model. J. Atmos. Sci., 62, 3741-3757, https://doi.org/10.1175/JAS3571.1.

— S.-Y. Kim, and S. Min, 2018a: Widening of the Hadley cell from Last Glacial Maximum (LGM) to future climate. J. Climate, 31, 267-281, https://doi.org/10.1175/JCLI-D-170328.1.

— Antarctic ozone depletion: An update with ChemistryClimate Model Initiative (CCMI) models. Environ. Res. Lett., 13, 054024, https://doi.org/10.1088/1748-9326/aabf21.

Staten, P. W., J. Lu, K. M. Grise, S. M. Davis, and T. Birner, 2018: Re-examining tropical expansion. Nat. Climate Change, $\mathbf{8}$, 768-775, https://doi.org/10.1038/s41558-018-0246-2.

Taylor, K. E., R. J. Stouffer, and G. A. Meehl, 2012: An overview of CMIP5 and the experiment design. Bull. Amer. Meteor. Soc., 93, 485-498, https://doi.org/10.1175/BAMS-D-11-00094.1.

Toggweiler, J., and J. Russell, 2008: Ocean circulation in a warming climate. Nature, 451, 286-288, https://doi.org/10.1038/nature06590.

Vallis, G. K., P. Zurita-Gotor, C. Cairns, and J. Kidston, 2015: Response of the large-scale structure of the atmosphere to global warming. Quart. J. Roy. Meteor. Soc., 141, 1479-1501, https://doi.org/10.1002/qj.2456.

Walker, C. C., and T. Schneider, 2006: Eddy influences on Hadley circulations: Simulations with an idealized GCM. J. Atmos. Sci., 63, 3333-3350, https://doi.org/10.1175/JAS3821.1.

Wang, N., D. Jiang, and X. Lang, 2018: Metric-dependent tendency of tropical belt width changes during the Last Glacial Maximum. J. Climate, 31, 8527-8540, https://doi.org/10.1175/ JCLI-D-18-0199.1.

Waugh, D., and Coauthors, 2018: Revisiting the relationship among metrics of tropical expansion. J. Climate, 31, 75657581, https://doi.org/10.1175/JCLI-D-18-0108.1.

Wilcox, L. J., A. J. Charlton-Perez, and L. J. Gray, 2012: Trends in austral jet position in ensembles of high-and low-top CMIP5 models. J. Geophys. Res., 117, D13115, https://doi.org/10.1029/ 2012JD017597. 